\title{
A Second Chance: The University of Cape Town's Diploma in Education
}

\author{
JUNE SALDANHA
}

$\mathrm{T}$ his article describes a curriculum that gives men and women from predominantly black working class communities a second chance to acquire a formal qualification at a higher education institution in South Africa. The curriculum provides the space for adult students to think critically about themselves and their practice and to develop a confident voice to express themselves. Through this process they develop both learner and educator identities and begin to see how the two intersect. The article gives some of the historical background of the course, and shows how lecturers who have taught on the programme at different times have helped shape the curriculum. It goes on to discuss the changing nature of the student intake, the curriculum content and structure and ends with a discussion of the impact of the course, on students, staff and on the university as a whole. One very visible impact of the diploma is to be seen in the students who have gone on to acquire other postgraduate qualifications in adult education studies. On a university-wide level through the involvement of adult 
education lecturers in other programmes and curricula, knowledge of and interest in adult learning is shared and encouraged.

THE DIPLOMA IN EDUCATION: HISTORICAL DEVELOPMENT

The Diploma started in the mid-1980s, at the time of popular mobilisation against apartheid and the growth of local civic organisations. It was housed within what was the Department of Adult Education and Extramural Studies in the Faculty of Education. The Community Adult Education Programme (CAEP), as it was then called, was a response to requests from civic organisations for leadership training. It began as a series of short courses and workshops, providing a space for community and political activists to meet and talk to each other. Essentially, it provided capacity building for these activists who were involved in political education in their communities and trade unions. In 1987 these short courses became part of a year-long, non-credit bearing programme that broadened the student base to include people from community-based organisations, such as youth, women's groups and housing activists.

As well as these outside influences, the experiences, interests and passions of successive convenors have been instrumental in shaping the curriculum and student composition of the course. For example, Anne Hope, a Freirian adult educator, encouraged learners from women's groups and community-based health organizations to join the programme, whilst Linda Cooper drew a larger trade union constituency into the class. In the early 1990s, Jean Gamble introduced an industrial workplace element. She initiated the Workplace Learning Programme (WPL), a year-long non-credit bearing programme of weekly seminars aimed specifically at workplace trainers, which was run in parallel to CAEP for three years. Since there was a fair amount of overlap between CAEP and the WPL, and a growing interest in these programmes by both trade unionists and community activists, the two streams were merged and formalised into a two-year, credit-bearing Certificate in Adult Education Training and Development, which subsequently became the Diploma in Education (Adult Education) in 2000.

In 1994, after the first democratic elections following the end of apartheid, changes in the national education and training policy meant that people who were facilitating accredited qualifications 
needed to be qualified education, training and development practitioners themselves. (Department of Education and Department of Labour 2003, p. 11).

This has elevated the status of adult learning and further stimulated an interest in an accredited professional qualification. A new national qualifications framework was developed to address the previous inequalities of the apartheid education and training system. As a result, a 'Recognition of Prior Learning' path (RPL) was introduced at the University of Cape Town (UCT), which allowed students to be accepted on the basis of their experience, rather than the traditional formal marks-based entry requirement (Republic of South Africa 2002, p. 11). As well, students who cope well on the Diploma are able to access other qualifications in the adult education stream, namely the Advanced Certificate in adult education, and in some cases have gone on to do a Master's degree.

This recognition of prior education and training experience is considered to be an important admission criterion for two reasons. Firstly, the majority of students growing up during the apartheid era would not have had the opportunity to complete their schooling. Secondly, throughout the course, opportunities are created for students to reflect on their experience and use their insights to make sense of the theory and vice versa.

Over the years, as the political landscape has changed, so too has the student composition and curriculum. 'I'm very aware [that] it has mirrored the changes out there', says a lecturer on the Diploma. 'So as the political landscape has changed, we don't get the same kind of political activists; it's much more people who're working, who actually see their career in a training context and who want to get a proper professional qualification.' This demand for learning in order to further career advancement rather than for political mobilization has also been influenced by the changes in education and training policy, as mentioned. One of these policy reforms was the introduction of a skills levies fund for people who were previously discriminated against by apartheid policies, namely, black people, women and disabled people. Under this levy, companies pay a percentage of their payroll to the fund, which is used for education and training, and the fund can be accessed by companies wishing to support staff training. 
Today, the Diploma in Education (Adult Education) is a two-year part-time credit-bearing programme that targets adult education and development practitioners in the community and workplace who wish to obtain a professional qualification (http:/ / web.uct. ac.za/depts/educate/adult.php). It is based in the Higher and Adult Education Studies and Development Unit (http:/ / www.haesdu.uct. ac.za/), which is a department of the Centre for Higher Education Development (CHED; http:/ / www.ched.uct.ac.za/home/), at UCT.

\section{THE STUDENTS}

The student group is diverse with regard to race, socio-economic status, age, language and gender. The majority of the students are black women with an age range of 24-57 years. Most of the students' first language is Afrikaans or isiXhosa. Students are required to learn in English since it is the medium of instruction at the university. The current 'community' cohort includes community educators mainly from NGOs (for example, early childhood organisations, health and HIV / AIDS organizations, women's groups, first aid organizations, shelters for homeless people) and public sector workplaces (for example, the prisons and police ) or parastatal organisations (for example, Transnet, the government-owned freight transport company) as well as educators from communitybased employment-generating projects. A second group consists of educators based in trade unions and a third includes trainers from the telecommunications sector. The fourth and fifth groups of students includes trainers who are responsible for coordinating and facilitating learnerships in their workplaces - work-based learning programmes that also include a formal component. These cohorts are funded by the Clothing, Textile, Footwear and Leather (CTFL) SETA and the Transport SETA, respectively (SETA, or Sector Education Training Authority, approve learnerships and manage the skills levies). All the students are responsible for education and training at their sites of practice.

The Diploma is designed to be responsive to the different groups of students, and there are a number of versions of the curriculum, tailored to meet the needs of learners from different contexts. For example, the curriculum for the trade union educators is negotiated with Ditsela (http:/ / www.ditsela.org.za/ditsela/), a national trade 
union education body, to ensure that it is grounded in the trade union context. The course is delivered jointly by the University and Ditsela, and is designed and facilitated by staff and educators from the trade unions. The curricula for the students from the Telecommunications sector, Clothing, Textiles, Footwear and Leather Seta, and Transport Seta are also customized to meet the needs of learners from these contexts.

Through the Diploma we have been able to build strategic partnerships with local industries and organized labour, which allows for direct engagement and negotiation over curriculum.

The curriculum is thus continuously revised to meet the needs of particular sites of practice in the education, training and development field. This is done through partnerships with organizations and relationships built with organizations through past and current students.

However, the curriculum also challenges students to develop a critical lens to interrogate the purpose of education and training within their workplaces and deepen their insight into the political, social and economic influences on their learning and practice. Furthermore, despite the changing student composition and changing curriculum, lecturers agree that the fundamental aim of the Diploma remains constant: to develop students' knowledge, skills and values to enable them to facilitate the learning of other adults though a reflection on practice. This happens through critical reflection and a development of theoretical understanding. Thus opportunities for examining their work as educators, and for the development of their professional identity, are central to the curriculum.

\section{THE CURRICULUM}

We draw on different approaches to curriculum but place a high value on experiential learning alongside humanist and socially critical frameworks. These approaches all emphasise self-realization in an individual or social context. Students are helped to reflect on their experience and engage in a meaningful way with their learning experiences in different contexts. Validating their experience through reflection and acknowledgement is affirming and builds their selfconfidence. Students use the theoretical frameworks gained from the course to deepen their insights and understanding of their 
experiences. This helps them to interpret their interactions with the world. The curriculum does not impose a particular worldview on learners but encourages them to understand different positions and then begin to challenge their own worldviews through a different lens. We are not suggesting that education is neutral. On the contrary, we want to echo the views of Julius Nyerere that 'adult educators cannot be politically neutral. The very nature of their work is to activate the people and arouse their consciousness' (Hope 2007, p. 13). As facilitators, our own voices and experiences are evident in the design of the curriculum.

The current curriculum is based on a two-year, part-time programme during which the personal and professional identity of the students is progressively built. Each year the students complete three modules. In the first year, students complete: Introduction to Adult Learning, Organizational Development, and Designing and Facilitating Learning Events.

The first module, Introduction to Adult Learning, builds learner confidence. We recognize that many people enter the course with very low self-esteem as learners and their re-entry into formal learning is challenging. This module creates a safe space for them to reflect on themselves as learners and deepen their understanding of how race, gender, class and culture have influenced their learning. By mapping of their own history they reflect on the factors that helped and hindered their learning. Through this process of exploration they discover that for some the right to education was violated, that gender has negatively influenced learning in the context of work and home and that in many instances poverty has been a major factor that hindered their learning as children and continues to be a major block in adult years. This creates the space for marginalized students to raise their 'voices' and break their silences.

Butterwick (2005, p. 260) reminds us that there is a growing recognition for the need to explore the multiple meanings of silence. Many students' experiences in other social contexts have silenced them. Butterwick (2005, p. 260) also explains that 'silences can be a place of deep learning' and Walters and Manicom (1996, p. 16) note that 'educators must be sensitive to the context of silences and the power relations that they reflect'. This can be a hard and painful 
process and for some students reflecting on their own learning brings to the fore feelings of resentment, anger and embarrassment. A student shared his insight during this module and said, 'I now understand why my parents did not allow me to continue learning. They could not afford it. Throughout my life and now I am 50 years old; this has created tensions between us. I called them to apologise and invited them to my graduation'. Students also explore learning as a resource and reflect on what has encouraged their learning; this reinforces positive thinking about themselves as learners.

Through this process of engaging with their own learning, students begin to develop an understanding of themselves as learners with a 'voice', which is influenced by their 'positionality and constant changing identities' (Tisdell 2000, p. 176). Throughout the course opportunities are created to strengthen this voice and understand the silence. A female student very courageously shared:

I was abused all my life, even while doing the diploma. This course gave me the insight to understand why I did not have the confidence to learn and succeed. I was afraid of male lecturers, thought I was stupid and did not show much respect for my learners. This has changed. I am sensitive to their needs. Perhaps they were also abused. I respect them. I am a different person at home. I say what I do not like. My husband stopped abusing me. He came to my graduation and shouted when I received my Diploma, 'Dit is my vrou' (That is my wife). Yes, he was the one who swore at me when I studied, 'You fucking mad ... You and your University things. I don't know why they send stupid people to university ... you have not even got a Matric certificate. This is a fraudulent thing. Something's not right here. But you will have to prove to me'.

After reflecting on personal experiences, the orientation shifts outwards in the second module, Organisational Development. Here, students draw on relevant theory and through reflection on their own practice they begin to understand how the broader contextual structures and processes influence learning within organizations and groups. Students struggle to talk about issues of race and gender since it forces them to confront their own prejudices and revisit their painful experiences of growing up in an apartheid society. One student was quite irritated and said, 'This module helped me to look 
more closely at my organization. I never thought about how race and gender was influencing changes in the organization. I don't like this race and gender stuff but I can see what it is doing to my growth in the workplace'.

The third module, Designing and Facilitating Learning Events, aims to locate this organisational experience in a wider, societal context. Through planning and implementing a 'learning event', students apply the knowledge and skills gained from the earlier modules to develop a deeper understanding of their professional experience. Students are required to design and facilitate an educational workshop that addresses the learning needs of people at their site of practice. Learners reflect on their own identity as facilitators and this helps them to understand how this influences their work as educators.

Students are also introduced to popular education and the Freirian methodology in this module. The aim is to make their voices more assertive as they reflect on and build confidence in their own professional experience. A student made a very interesting comment: 'Freire sounds too political. I stay away from politics. But you know what, what he says make sense. Educators must show respect to learners. They must teach their learners to respect others. We must be critical. I must agree that there is [sic] people at my work who want the power and want us to keep quiet. Yes, there is a "culture of silence at my workplace"'.

In the second year, the students again complete three modules. The first, Foundations of Adult Learning Theory, introduces learners to different worldviews on the purpose of adult learning. This helps them to understand and confront the social purpose of their own work as education, training and development practitioners. They also learn about the history of adult education in South Africa and try to map where they and their learners were during these historical periods. Students commented:

'I never liked history. It was boring. This adult education history makes sense.'

'This mapping activity told me that I am part of the history.' 'The session on the history of skills made me sit and think.' 'I now know why people think that my job is not as important 
as theirs. Do you have a book for me to read. I want to learn more. This stuff is making me empowered.'

They also try to identify different adult education approaches used during these periods and revisit the work of Paulo Freire. In addition, they begin to examine the impact that globalization has on their own learning and the learning that occurs in their communities and workplaces.

The second module, Fields and Sites of Education, Training and Development Practice, introduces learners to South Africa's education and training policy framework and locates learning in a national and international context. Students are introduced to the culture of human rights as they explore how the qualifications framework gives people access to education, and debate whether people's right to education can be upheld in the absence of resources. This theoretical understanding helps them to look at their own learners' experiences and develop an understanding of the impact of policy on learning. The aim is to sharpen their practitioner lens and build their capacity to think critically about the fact that legislation may be enabling but is not always implemented. A student commented: 'I have rights! You must show me how I can see that this [sic] policies are implemented'. As facilitators we must build into this module a session on 'How to access your rights' and must create the space to share and learn 'How to build activism'.

The final module, Field Study, consolidates student learning through specialization in an education, training and development practitioner role, such as materials developer, education evaluator, designer or assessor. Depending on their choice students are required to design material, conduct an assessment or an evaluation, or design an online learning course. By drawing on the broad knowledge base that they have gained from the previous modules, students are able to deepen their theoretical understanding of their role specialization and are able to see it in the context of their own education, training and development practices.

A lecturer on the Diploma explains: 'The second year replicates the first in the sense of moving from the personal to the broader context, but at a more demanding level. This approach is the opposite of other professional development courses, where students begin with a theoretical framework and slowly move to practice. The Diploma 
moves between theory and practice: it starts with a reflection on experience, moves inductively towards theory, and then moves back from theory towards application'.

The theme that cuts across the curriculum is the two-way relationship between context and learning. As facilitators of the Diploma, we would argue that while context does act to shape learning in very particular, obvious ways, learning can also enable agency and thereby educators' ability to impact on contexts. We do acknowledge, however, that in contexts such as the workplace, power relations limit their agency. Research by Jones (2005) indicates that it is extremely difficult for learners who return to the workplace to intervene and facilitate change at their site of practice. However, their experience of learning does give them agency to make some difference in certain areas of their lives.

\section{DeVELOPING STUDENTS' LEARNER AND EDUCATOR IDENTITIES}

Most of the students come from disadvantaged backgrounds and have had negative experiences with past formal learning. The Diploma recognizes that the negative influences on their learning have also silenced them and thus the course begins with a focus on themselves. A lecturer who taught on the Diploma explains that 'the curriculum provides an opportunity for the development of personal confidence. This is done by starting the course with a focus on personal learning experiences, demonstrating that adult students are able to contribute their own knowledge of particular situations; from this, their learning identity emerges, and they start relating to theory and asking questions'.

The course helps students develop a deeper understanding of their multiple social identities, and to see how these influence the way they facilitate learning and relate to their learners. We hold a nonessentialist view of identity and self esteem which argues that there are multiple identities that are in constant change and are sometimes in conflict with each other (Hayes \& Flannery 2000, p. 57). This gives students the potential agency to choose to change their identity.

Throughout the course students learn, unlearn and relearn their identities and struggle with the tensions and contradictions that begin to surface in their personal lives, communities, workplaces and society. The course not only develops participants as learners 
and practitioners, but also helps them to 'read the world' and to gain insights about what is happening at their own sites of practice.

Research by a Masters student (February 2003), confirms the value of the relationship between personal experience and theory in the curriculum, and reveals that one of the biggest gains for students is the increase in their level of personal confidence. A lecturer on the Diploma observes that 'one of the main outputs ... is assertiveness, confidence and willingness to take on bigger issues at a level where they [the participants] know they can be effective, and then start asking questions in other levels as well'. Feedback from students' assignments reflects that this happens in both personal and professional contexts.

\section{IMPACT OF THE DIPLOMA}

Through the diploma we have become more aware of the needs of adult learners who return to or enter a Higher Education Institution (HEI) for the first time, where the institutional culture and environment is orientated towards the learning of younger undergraduates. Research is being undertaken through the Adult Learner Working Group, a cross-faculty group at UCT, to understand the factors that influence the learning of mature students. This group was formed to lobby more widely for adult learners who have over the years not been recognized as an important category of learners. It works with the Cape Higher Education Consortium (CHEC; http:// www.chec.ac.za/) and other HEIs to advocate for the needs of adult learners.

Student evaluations of the Diploma have generally been extremely positive in terms of personal learning and growth as educators. Participants indicated a growing confidence in their role as educators and trainers, and a better and deeper understanding of both their own and other students' education and training practices. This important aspect of the course - the opportunity to meet other learners - is often overlooked. The social networking that occurs is evidence of the value of interacting with other learners.

Lastly, the experience gained in the Diploma programme has had an impact on UCT more widely. For example, the use of RPL as an alternative path for adult students to access higher education has led to the development of an institution-wide policy on RPL, 
largely brought about by staff from the Diploma in Education and other university staff collaborating in the Adult Learners Working Group. A number of students who have entered through RPL have done exceptionally well. In the 2008 intake, for instance, four students made the Dean's merit list and three students from former years went on to do their Master's degrees: two have passed while another graduated with distinction. It is also worth noting that a number of former students who did well on the Diploma have returned as tutors. Diploma staff have served as curriculum advisors on a number of programmes serving adult learners for example, the Master's in Disability Studies and the Disaster Mitigation for Sustainable Livelihoods Programme (DIMP).

Diploma Staff who have PhDs and Master's have focussed their research on issues of adult pedagogy, particularly for students coming from historically disadvantaged communities. All educators who teach on the Diploma programme have 'adult learning' expertise, which has proved invaluable in supporting an increasing number of programmes at UCT wanting to design curricula that reflect adults' experiences, learning and workplace realities.

\section{Conclusion}

The diploma has given many students from black working communities a second chance to learn and embark on a journey of lifelong learning. The diploma has built the confidence of learners and impacted their lives in significant ways. The changing political landscape has seen more students wanting to do the course to further their career in education and training, but the particular nature of this diploma has given them a critical lens to reflect on their learning and practices and through this process students emerge with a deeper understanding of themselves and of the field of education, training and development. The diploma has since its inception been responsive to the needs of individuals and organisations and continues to customise the curriculum through engagement with organisations. The diploma has also impacted on the University itself, particularly through the recognition of prior learning, which has made it possible for many diploma students to access learning. Very importantly, the work in the diploma over the last nine years has helped to build a critical base of knowledge about adult learning. 


\section{REFERENCES}

Butterwick, S 2005, 'Feminist pedagogy', in M English (ed.), International Encyclopedia of Adult Education, Palgrave Macmillan, New York, pp. 257-262.

Department of Education and Department of Labour 2003, 'An interdependent national qualifications framework', consultative document, Government Printers, Pretoria, July.

February, C 2003, 'What counts as useful knowledge? Perceptions of a group of adult learners in Higher Education', Master's thesis, University of Cape Town, Cape Town.

Hayes, E \& Flannery, D 2000, Women as learners. The significance of gender in adult learning, Jossey-Bass, San Francisco.

Hope, A 2007, 'Building a convivial society: Insights from Nyerere and Freire', lecture presented at the fourth Vice Chancellor's Julius Nyerere Annual Lecture on Lifelong Learning, University of Western Cape, Cape Town, 20 August, viewed 20 May 2009, http://www.icae.org.uy/eng/nyererelecturepaperannehopeaug07.pdf

Jones, B 2005, 'Student perceptions of how their learning experiences, on a University Diploma in Education, impacted on their workplace practices and identity: A case study of emerging education, training and development practitioners in the clothing industry in the Western Cape', unpublished Master's thesis, University of Cape Town, Cape Town.

Republic of South Africa 1995, South African Qualifications Authority Act (Act No. 58 of 1995), Government Gazette, No. 1521, 4 October.

Tisdell, EJ 2000, 'Feminist pedagogies', in E Hayes \& S Flannery (eds), Women as learners. The significance of gender in adult learning, Jossey-Bass, San Francisco, pp. 155-184.

Walters, S \& Manicom, L (eds) 1996, Gender in popular education, Zed Books, London.

Information for these case profiles was sourced from interviews conducted by Linda Cooper, Janice McMillan and June Saldanha with the Institutional Planning Department, University of Cape Town, in October 2007. 